\title{
Determinação da qualidade de vinhos artesanais produzidos na Mesorregião do Noroeste Rio-Grandense
}

\author{
Natália Ambrósio*, Luciana Dornelles Venquiaruto**, Rogério Marcos Dallago***, \\ Rozelaine de Fatima Franzin****, João Carlos Krause ${ }^{\star \star \star \star \star}$, \\ Bethina Pascuetti Tres ${ }^{\star \star \star \star \star \star}$, Nadia Ligiamara Dewes Nyari ${ }^{\star \star \star \star \star \star \star}$
}

\section{Resumo}

O vinho é uma bebida obtida da fermentação alcoólica da uva madura e fresca ou do suco de uva fresco. Sua definição bioquímica é caracterizada como bebida proveniente da fermentação alcoólica dos açúcares de suco de uva pelas leveduras e, em alguns casos, pelas bactérias lácticas. A presente pesquisa objetiva conhecer a realidade da qualidade de vinhos artesanais comercializados em feiras de produtores ou adquiridos diretamente em propriedades rurais. Pretende-se analisar quantitativamente, por meio de análises físico-químicas, determinados parâmetros, como: o teor alcoólico e a acidez total de vinhos tintos e brancos produzidos e comercializados na Mesorregião do Noroeste Rio-Grandense. A região em estudo possui uma significativa quantidade de produtores rurais que produzem vinhos para agregar valores às atividades desenvolvidas nas suas propriedades. Os vinhos artesanais são amplamente consumidos na região pesquisada por questões culturais, devido à sua qualidade sensorial diferenciada e também pelos benefícios que traz a saúde, quando consumidos de forma moderada. No caso do vinho, a determinação de acidez e teor alcoólico fornece um dado importante do estado de conservação do produto, uma vez que, na produção artesanal do vinho, um dos principais problemas está relacionado com a acidificação precoce do produto mediante a transformação do álcool em ácido acético, já que não há um efetivo controle na hora da fabricação, bem como na conservação do produto, uma vez que as boas práticas de fabricação pouco são conhecidas ou praticadas.

Palavras-chave: Análises físico-químicas. Qualidade. Vinho artesanal.

* Universidade Regional Integrada do Alto Uruguai e das Missões - Campus Erechim. E-mail: nati_ambrosio07@ outlook.com

* Universidade Regional Integrada do Alto Uruguai e das Missões - Campus Erechim. E-mail: venquiaruto@ uricer.edu.br

*** Universidade Regional Integrada do Alto Uruguai e das Missões - Campus Erechim. E-mail: dallago@uri.com.br

*t*** Universidade Regional Integrada do Alto Uruguai e das Missões - Campus Erechim. E-mail: rozelaine@san.uri.br

**** Universidade Regional Integrada do Alto Uruguai e das Missões - Campus Erechim. E-mail: krause@san.uri.br

...... Universidade Regional Integrada do Alto Uruguai e das Missões - Campus Erechim. E-mail: bhetinapascuetti@ gmail.com

..m*t**Faculdade La Salle, Lucas do Rio Verde, Mato Grosso, Brasil. E-mail: nadialigiamara@hotmail.com 


\section{Introdução}

Segundo o Decreto no ${ }^{\circ}$ 8.198, de 20 de fevereiro de 2014, vinho é a "[...] bebida obtida pela fermentação alcoólica do mosto simples da uva sã, fresca e madura" (BRASIL, 2014a, não paginado). O vinho é considerado uma das primeiras criações da humanidade, sua história é longa e muito antiga. Para Côrte Real (1993, p. 15), “[...] o vinho deve ter surgido por acaso em muitos pontos da Terra, já que a fermentação se realiza espontaneamente, em uvas acidentalmente esmagadas, promovida pelas leveduras que habitam suas cascas". Não se pode, portanto, apontar com precisão o local ou a época que o vinho foi feito pela primeira vez (GAUTO; ROSA, 2011).

Segundo Cataluña (1988), a videira foi introduzida no Brasil por Martin Afonso de Souza, em 1532, na capitania de São Vicente, litoral de São Paulo, que, em sua expedição, trouxe agricultores experientes em viticultura da Ilha de Madeira e Açores.

O primeiro vinho do Brasil foi produzido em São Paulo, em 1551, no bairro de Tatuapé, onde foram plantadas as videiras que Brás de Cuba tentou fazer vingar, mas sem sucesso. De forma que os vinhedos foram transferidos para a capitania de São Vicente.

No Rio Grande do Sul, as missões jesuítas cultivavam vinhedos, porém, com as crescentes disputas entre os colonizadores espanhóis e portugueses e o massacre das missões, a imensa maioria, se não tudo, acabou sendo destruída. O renascimento dos vinhedos no Rio Grande do Sul se dá com a chegada dos imigrantes açorianos, a partir de 1732. A Manoel de Macedo Brum é atribuída a primazia na industrialização de vinhos tinto, branco e também de vinagre e destilados do bagaço da uva (SIMON, 2001).

No entanto, o grande marco da vinicultura sul-rio-grandense se deve à imigração italiana, a partir de 1875. Esses imigrantes trouxeram consigo mudas de videiras europeias, que, uma vez plantadas, se adaptaram muito bem, porém, foram dizimadas por doenças fúngicas. Esses mesmos imigrantes exploraram, então, outras variedades já adaptadas ao Brasil, como a videira americana Vitis labrusca, variedade Isabel, introduzida no Brasil no ano de 1840. Atualmente, esta é a variedade predominante nos parreirais gaúchos (SOUZA, 2005).

Segundo o Panorama da Vitivinicultura Brasileira, o número de empresas vinícolas no Rio Grande do Sul atualmente é de 673. Na safra de 2017, foram processados $753.219 .520 \mathrm{~kg}$ de uva, dos quais 50,9\% foram destinados à produção de vinhos e derivados, obtendo-se 297.773.414 litros. De 2016 a 2017, observou-se um aumen- 
to de $2,19 \%$ na produção em litros de vinhos de viníferas e de mesa (INSTITUTO BRASILEIRO DO VINHO, 2018). Sabe-se que esse número deve ser muito maior, pois existem muitos produtores de vinhos que não têm nenhum tipo de cadastro. Esses produtores com pequena área em torno de sua localidade que produzem vinho para consumo interno são o objeto de estudo deste trabalho.

A Mesorregião do Noroeste Rio-Grandense é uma das sete do estado brasileiro do Rio Grande do Sul. É formada pela união de 216 municípios agrupados em treze microrregiões, sendo estas: Carazinho, Cerro Largo, Cruz Alta, Erechim, Frederico Westphalen, Ijuí, Não-me-Toque, Passo Fundo, Sananduva, Santa Rosa, Santo Ângelo, Soledade e Três Passos.

A região em estudo possui uma significativa quantidade de produtores rurais que produzem vinhos para agregar valor às atividades desenvolvidas nas suas propriedades. Os vinhos artesanais locais são amplamente consumidos, principalmente por questões culturais e devido às suas qualidades sensoriais diferenciadas. Na maioria das vezes, os vinhos são fabricados por pequenas agroindústrias, com o objetivo de obter uma renda extra no orçamento familiar. A matéria-prima, na maioria das vezes, vem da própria propriedade rural (dos parreirais) na qual é processada.

Segundo a Lei no 12.959 , de 2014: "O vinho produzido por agricultor familiar ou empreendedor familiar rural deve ser elaborado com o mínimo de $70 \%$ (setenta por cento) de uvas colhidas no imóvel rural do agricultor familiar e na quantidade máxima de 20.000 L (vinte mil litros) anuais" (BRASIL, 2014b, não paginado). E, ainda: "A comercialização do vinho produzido por agricultor familiar ou empreendedor familiar rural deverá ser realizada diretamente com o consumidor final, na sede do imóvel rural onde foi produzido, em estabelecimento mantido por associação ou cooperativa de produtores rurais ou em feiras da agricultura familiar" (BRASIL, 2014b, não paginado).

A elaboração do vinho artesanal é feita, geralmente, da seguinte forma:

I. Esmagamento e desengaçamento: rompe-se o grão da uva para liberar o suco. A casca fica em contato com o grão, no caso do vinho tinto, por um período que varia conforme o tipo de vinho que se quer; no caso da produção artesanal, o período varia conforme os conhecimentos dos produtores.

II. Fermentação: no caso de vinhos que ficam em contato com a casca, a fermentação é espontânea, já que as leveduras estão presentes na casca da uva. Utilizam-se, geralmente, tanques de madeira ou de aço inoxidável para tal procedimento. 
III. Descubagem e fermentação secundária: é a passagem do vinho de um tanque para outro, na qual também é feita a correção do mosto, adicionando açúcar, alguns produtores não transferem o vinho, somente adicionam 0 açúcar para a fermentação iniciar. Isso pode ser feito se os grãos da fruta estiverem num bom grau de maturação.

IV. Fermentação secundária: é feita em ambiente fechado, nas denominadas "pipas", que podem ser de madeira, plástico ou outros materiais.

V. Envasamento: após um determinado período de dias, que varia conforme o costume de cada produtor, o vinho é transferido para uma outra "pipa", para envelhecimento, ou vasilhames para a comercialização, os quais normalmente são garrafas PET de 2 litros.

A qualidade final do vinho depende de cada um desses processos, pois é quando as transformações químicas ocorrem, e são elas que determinam a qualidade final do produto.

O processo de vinificação pode ser considerado complexo, devido às etapas que ocorrem de forma simultânea. Alguns fatores são pertinentes às mudanças que ocorrem na composição química e sensorial dos vinhos ao longo da tecnologia de vinificação, desde a região produtora, o clima, o tipo de uva, até o manejo da videira. Esses fatores extrínsecos podem afetar a qualidade final de um vinho, mas fatores intrínsecos ligados à qualidade, como propriedades de cor, perfil químico, estabilização, aroma e safra, também podem interferir. Os fatores intrínsecos mencionados, exceto safra, estão diretamente relacionados ao processo de vinificação e são passíveis de variações ao longo do processo de transformação da uva em vinho (DE CASTILHOS, 2016).

Um envelhecimento adequado também é um importante fator que define algumas propriedades qualitativas. É comum, ainda nos dias atuais, o envelhecimento em barris de madeira, pois estes se mostram mais adequados, já que ocorrem alterações físico-químicas e sensoriais na bebida, conforme o tempo de contato da bebida com o material do barril. Sabe-se que o vinho extrai componentes da madeira, realizando, às vezes, até reações químicas, por isso a escolha do tipo de madeira do barril pode ser considerado um indicativo da qualidade final da bebida. $O$ ideal seria realizar o envelhecimento em barris de carvalho, mas outras espécies de madeira também podem ser usadas, com resultados semelhantes. Além disso, a madeira proporciona a decomposição de biopolímeros, como lignina, hemiceluloses e celulose, seguida da liberação de compostos derivados do vinho. $\mathrm{O}$ armazenamento em barris de madeira 
permite, ainda, a evaporação de compostos voláteis e a concentração de compostos não voláteis (CANAS, 2017).

No vinho, existem mais de 600 compostos químicos diferentes, incluindo a maioria das funções orgânicas mais importantes. Ele possui um $\mathrm{pH}$ ácido, porém, como a maioria dos ácidos são orgânicos, são relativamente fracos. Os principais ácidos presentes no vinho são: ácido tartárico, ácido málico e ácido cítrico; encontram-se, também, em menor quantidade, os ácidos láctico e succínico. $\mathrm{O}$ ácido acético também está presente, mas em quantidade mínima. Caso haja uma quantidade elevada de tal composto, pode-se concluir que o processo de fabricação da bebida foi realizado de forma incorreta, ocorreram acidentes na fermentação ou ataques bacterianos. Uma quantidade correta de tais compostos determina a qualidade do vinho obtido, garantindo textura, sabor e frescor adequados. Os açúcares presentes no suco da uva e adicionados durante a fermentação do mosto são transformados em etanol durante o processo de fabricação. Um teor alcoólico adequado garante bom sabor e cor ao vinho (ALPUIM, 1997).

Se os compostos químicos do vinho estão dentro dos padrões, a qualidade é garantida, e, com isso, os benefícios também. Estudos mostram que a ingestão moderada de vinho, isto é, uma a duas taças de vinho tinto por dia, traz benefícios à saúde (VACCARI; SOCCOL; IDE, 2009), pois, quando consumido de forma moderada, favorece a digestão, inibe o desenvolvimento de certos microrganismos patogênicos, contribui para a redução de problemas cardiovasculares, possui efeito antioxidante, que combate os radicais livres (RIZZON; DALL'AGNOL, 2007), além disso, há conclusões sobre uma atividade antitumoral de uma fração de polissacarídeos extraídos do vinho em ratos portadores de tumores (MARTINS et al., 2015). Porém, para que tais benefícios aconteçam, é necessário que a bebida atenda a parâmetros pré-estabelecidos. Por isso, ao longo da história, busca-se cada vez mais um padrão de qualidade que atenda aos critérios de saúde. A legislação brasileira possui leis que tratam do assunto e determinam parâmetros quantitativos para valores de acidez total e teores alcoólicos adequados.

Nesse contexto, a presente pesquisa objetiva conhecer a realidade da qualidade, em relação a acidez e teor alcoólico, de vinhos artesanais comercializados em feiras de produtores ou adquiridos diretamente na propriedade rural, os quais, na maioria das vezes, são comercializados sem uma avaliação quantitativa de parâmetros que indicam a sua qualidade. 
Pretende-se analisar quantitativamente, por meio de análises físico-químicas, determinados parâmetros, como o teor alcoólico e a acidez total de vinhos tintos e brancos, os quais permitem um indicativo da qualidade desses produtos.

\section{Metodologia}

O processo experimental foi realizado em um laboratório na Universidade Regional Integrada do Alto Uruguai e das Missões (URI), Campus Erechim. Foram utilizados equipamentos padrão para a titulação volumétrica, como bureta, erlenmeyer, pipetas volumétricas, além dos reagentes (solução de hidróxido de sódio 0,1 N) e do indicador ácido-base fenolftaleína.

As amostras analisadas foram coletadas em feiras de produtos coloniais e propriedades rurais produtoras de vinhos artesanais, em diferentes cidades que compõem a Mesorregião do Noroeste Rio-Grandense.

Para a determinação da acidez total, utilizou-se o método analítico de titulação volumétrica (BACCAN et al., 2013; HARRIS, 2011a; MENDHAM et al., 2011). Os principais requisitos para uma reação volumétrica são: possuir grande constante de equilíbrio e processar rapidamente. $\mathrm{O}$ ponto de equivalência ocorre quando a quantidade de titulante adicionado corresponde à quantidade necessária para uma reação estequiométrica com o titulado (HARRIS, 2011a). Para tanto, retirou-se, com o auxílio de uma pipeta volumétrica, uma alíquota de $10 \mathrm{~mL}$ da amostra de vinhos, a qual foi transferida para um erlenmeyer de $250 \mathrm{~mL}$, juntamente com $100 \mathrm{~mL}$ de água e 3 gotas de fenolfetaleína $0,1 \%$. Após uma etapa de homogeneização, procedeu-se à titulação com uma solução padrão de $\mathrm{NaOH} 0,1 \mathrm{~N}$ até a solução alterar sua coloração para uma tonalidade rosa permanente, indicando o término da titulação.

Com a quantidade de hidróxido de sódio consumida na análise, efetuaram-se os cálculos de acidez, segundo a equação 1 :

$$
\operatorname{Acidez}\left(m E q . L^{-1}\right)=\frac{V_{N a O H} * N * 1000}{v}
$$

Em que:

$\mathrm{V}_{\mathrm{NaOH}}=$ volume da solução de $\mathrm{NaOH}$ gasto na titulação $(\mathrm{mL})$;

$\mathrm{N}$ = normalidade da solução de $\mathrm{NaOH}$;

$v=$ volume da amostra $(\mathrm{mL})$. 


\section{Resultados e discussões}

A Portaria no 43, de 18 de maio de 2016, define que o vinho de mesa é uma bebida elaborada a partir da fermentação alcoólica do mosto simples de uva, devendo possuir acidez total de $40 \mathrm{mEq} / \mathrm{L}$ a $130 \mathrm{mEq} / \mathrm{L}$ e graduação alcoólica de 8,6\% a 14\% em volume, podendo conter até uma atmosfera de pressão a $20 \square \mathrm{C}$ (BRASIL, 2016).

Os resultados das análises referentes à acidez total das 45 amostras de vinhos analisadas, coletadas em 21 municípios da Mesorregião do Noroeste Rio-Grandense, encontram-se na Tabela 1. Salienta-se que as análises foram realizadas em triplicata. Observa-se que, das 45 amostras de vinho artesanal analisadas, 12 (negritadas) encontram-se fora dos parâmetros estipulados pela legislação, ou seja, os teores de ácido estão acima dos valores máximos exigidos pela portaria do Ministério da Agricultura, que exige teores entre 40 e $130 \mathrm{mEq} \cdot \mathrm{L}^{-1}$. Nenhuma amostra apresentou teores abaixo do limite exigido.

Tabela 1 - Acidez total em miliequivalente por litro para amostras de vinhos

\begin{tabular}{|c|c|c|c|}
\hline Amostra & Acidez total (meq/l) & Amostra & Acidez total $(\mathrm{meq} / \mathrm{l})$ \\
\hline Aratiba $1^{*}$ & $111,7 \pm 0,1$ & Estação 2* & $184,2 \pm 1,8$ \\
\hline Aratiba $2^{*}$ & $109,7 \pm 0,1$ & Floriano Peixoto** & $69,2 \pm 0,3$ \\
\hline Aratiba $3^{*}$ & $158,1 \pm 0,1$ & Ipiranga do Sul* & $138,6 \pm 0,3$ \\
\hline Aratiba $4^{* *}$ & $86,1 \pm 0,1$ & Mariano Moro 1* & $136,3 \pm 1,4$ \\
\hline Aratiba $5^{\star \star *}$ & $106,2 \pm 0,1$ & Mariano Moro 2* & $134,2 \pm 0,3$ \\
\hline Aratiba $6^{\star * \star *}$ & $94,6 \pm 0,1$ & Mariano Moro $3^{* *}$ & $99,4 \pm 0,6$ \\
\hline Aratiba $7^{\star *}$ & $94,3 \pm 0,1$ & Mariano Moro $4^{* *}$ & $80,2 \pm 0,2$ \\
\hline Aratiba $8^{*}$ & $141,7 \pm 0,2$ & Nova Barreiro* & $78,2 \pm 0,1$ \\
\hline Aratiba 9* & $112,7 \pm 0,1$ & Planalto $1^{\star *}$ & $88,4 \pm 0,1$ \\
\hline Aratiba $10^{* *}$ & $100,4 \pm 0,1$ & Sananduva** & $106,26 \pm 0,1$ \\
\hline Aratiba $11^{* *}$ & $89,1 \pm 0,1$ & São João da Urtiga 1* & $120,6 \pm 0,1$ \\
\hline Barra do Rio Azul 1* & $116,5 \pm 0,5$ & São João da Urtiga $2^{\star \star}$ & $87,4 \pm 0,2$ \\
\hline Barra do Rio Azul $2^{* *}$ & $98,0 \pm 0,1$ & São José do Ouro** & $73,1 \pm 0,1$ \\
\hline Barra do Rio Azul 3* & $114,4 \pm 0,1$ & São Valentin* & $118,5 \pm 0,2$ \\
\hline Erebango * & $133,6 \pm 1,2$ & Sarandi** & $100,4 \pm 0,1$ \\
\hline Erechim $1^{*}$ & $100,4 \pm 0,1$ & Severiano de Almeida* & $185,0 \pm 0,7$ \\
\hline Erechim $2^{* *}$ & $111,7 \pm 0,1$ & Três Arroios* & $135,1 \pm 0,8$ \\
\hline Erechim $3^{* * *}$ & $93,9 \pm 0,1$ & Tucunduva* & $139,4 \pm 0,2$ \\
\hline Erechim $4^{*}$ & $105,5 \pm 0,1$ & Tuparandi* & $78,5 \pm 0,1$ \\
\hline Erechim $5^{\star *}$ & $80,2 \pm 0,1$ & Viadutos $^{* *}$ & $137,0 \pm 0,1$ \\
\hline Estação 1* & $158,6 \pm 0,7$ & Jacutinga* & $101,25 \pm 0,3$ \\
\hline Jacutinga** $^{\star *}$ & $89,75 \pm 0,1$ & Planalto $2^{*}$ & $98,7 \pm 0,1$ \\
\hline Planalto $3^{*}$ & $104,25 \pm 0,3$ & & \\
\hline
\end{tabular}


A acidez é uma característica importante nos vinhos e está relacionada a uma série de compostos presentes naturalmente na uva (tartárico, o málico e o cítrico) ou gerados no processo fermentativo (láctico e succínico) (DE CASTILHOS, 2016). Uma das principais funções da acidez é a harmonização com pratos, acentuando a qualidade de determinados ingredientes ou minimizando o gosto salgado e apimentado de outros.

Apesar de importante, valores de acidez acima do estipulado em legislação, como os observados nas 12 amostras destacadas na Tabela 1, sugerem que houve falha em alguma(s) etapa(s) do processo, mais especificamente nas etapas de fermentação secundária e/ou envasamento/armazenamento, as quais devem evitar/minimizar o contato do vinho com o ar atmosférico, mais especificamente o oxigênio, principal responsável pela acidez dos vinhos. Na presença de oxigênio, o vinho tende a se transformar em vinagre mediante a oxidação do álcool etílico em ácido acético (DE CASTILHOS, 2016; CATALUÑA, 1988).

Em termos de envasamento/armazenamento, a reutilização das garrafas, que é uma prática corriqueira, principalmente de pequenos produtores rurais, pode estar contribuindo para esta acidez, mediante a introdução de microrganismos estranhos ao vinho armazenado. Neste aspecto, recomenda-se sempre utilizar garrafas novas, preferencialmente escuras, para evitar a fotoindução da oxidação do vinho.

Os resultados das análises referentes à graduação alcoólica das 45 amostras de vinhos analisadas, coletadas em 21 municípios da Mesorregião do Noroeste Rio-Grandense, encontram-se na Tabela 2. As análises foram realizadas em triplicata. 
Tabela 2 - Teor alcoólico em ${ }^{\circ} \mathrm{GL}$ para amostras de vinhos tintos, brancos, rose e Isabel

\begin{tabular}{|c|c|c|c|}
\hline Amostra & Teor alcoólico $\left({ }^{\circ} \mathrm{gl}\right)$ & Amostra & Teor alcoólico $\left({ }^{\circ} \mathrm{gl}\right)$ \\
\hline Aratiba $1^{*}$ & 10,8 & Estação $2^{*}$ & 10,2 \\
\hline Aratiba $2^{*}$ & 9,6 & Floriano Peixoto** & 9,2 \\
\hline Aratiba $3^{*}$ & 8,9 & Ipiranga do Sul* & 13,6 \\
\hline Aratiba $4^{* *}$ & 8,6 & Mariano Moro $1^{*}$ & 13,4 \\
\hline Aratiba $5^{\star \star \star}$ & 12,2 & Mariano Moro $2^{*}$ & 13,2 \\
\hline Aratiba $6^{* \star * *}$ & 14,0 & Mariano Moro $3^{\star *}$ & 9,3 \\
\hline Aratiba $7^{* \star}$ & 12,3 & Mariano Moro $4^{\star *}$ & 8,7 \\
\hline Aratiba $8^{*}$ & 14,0 & Nova Barreiro* & 12,9 \\
\hline Aratiba $9^{*}$ & 11,7 & Planalto** & 8,9 \\
\hline Aratiba $10^{\star *}$ & 10,4 & Sananduva ${ }^{* *}$ & 13,7 \\
\hline Aratiba $11^{* *}$ & 9,8 & São João da Urtiga $1^{*}$ & 12,1 \\
\hline Barra do Rio Azul 1* & 12,5 & São João da Urtiga $2^{* *}$ & 8,7 \\
\hline Barra do Rio Azul $2^{\star *}$ & 9,0 & São José do Ouro** & 12,2 \\
\hline Barra do Rio Azul 3* & 13,4 & São Valentin* & 11,6 \\
\hline Erebango * & 13,7 & Sarandi** & 10,4 \\
\hline Erechim $1^{*}$ & 10,5 & Severiano de Almeida* & 13,0 \\
\hline Erechim $2^{\star \star}$ & 11,7 & Três Arroios* & 12,0 \\
\hline Erechim $3^{\star \star \star}$ & 9,6 & Tucunduva* & 13,9 \\
\hline Erechim $4^{*}$ & 10,8 & Tuparandi* & 8,8 \\
\hline Erechim $5^{\star *}$ & 8,6 & Viadutos $^{* *}$ & 10,1 \\
\hline Estação $1^{*}$ & 12,6 & Jacutinga* & 9,68 \\
\hline Jacutinga** & 10,2 & Planalto $2^{*}$ & 10,0 \\
\hline Planalto $3^{\star *}$ & 13,5 & & \\
\hline
\end{tabular}

Observa-se que, das 45 amostras de vinho artesanal analisadas, todas se encontram dentro dos parâmetros exigidos pela lei, ou seja, os teores alcoólicos estão dentro dos limites estabelecidos pelo Ministério da Agricultura, que exige teores entre $8,6 \%$ e $14 \%(\mathrm{v} / \mathrm{v})$.

\section{Conclusões}

$\mathrm{Na}$ presente pesquisa, foram analisadas 45 amostras de vinho artesanal de alguns dos municípios da Mesorregião do Noroeste Rio-Grandense. Foram determinados teores de acidez total e teores alcoólicos presentes nas amostras. Das 45 amostras analisadas, em relação ao teor alcoólico, todas as amostras estão dentro 
dos parâmetros exigidos pela legislação - 8,6\% a 14\% (v/v); já em relação ao teor de acidez total, 12 amostras apresentam teores acima dos exigidos pela legislação (40 a 130 mEq.L ${ }^{-1}$ ), mas nenhuma está abaixo desse parâmetro.

Os resultados obtidos foram encaminhados aos produtores e, dentro do possível, as suas dúvidas foram sanadas, uma vez que eles se mostraram muito interessados na proposta de pesquisa, pois, durante anos de produção da bebida, eles possuíam como parâmetros qualitativos exclusivamente análises sensoriais, as quais impossibilitam um comparativo com a legislação vigente.

Teores de acidez acima do exigido comprometem a qualidade do vinho, promovendo alterações na textura e no frescor da bebida. Em relação ao teor alcoólico, quando excede o permitido, pode influenciar no sabor e até na cor da bebida.

Aos produtores que possuem vinhos muito ácidos, o retorno é feito de uma forma mais especial, já que se procura entregar também possíveis soluções para o problema. Sabe-se que um vinho acidifica quando entra em contato com o oxigênio do ar, devido à oxigenação dos compostos. Dessa forma, é importante ressaltar aos produtores a importância de vedar bem os tanques de armazenamento e tomar um cuidado especial ao retirar a bebida dos tanques na hora do consumo, para evitar sua oxigenação. Além disso, como a qualidade final depende de todo o processo de fabricação, escolher bem os grãos da uva, cuidar ramos, folhas e frutos azedos, verdes ou demasiadamente maduros, que possam estar presentes no mosto e liberar substâncias indesejadas, são alguns cuidados que garantem uma qualidade mais elevada ao produto.

Paralelo a isso, a pesquisa ajudou a traçar um parâmetro da qualidade dos vinhos artesanais produzidos e comercializados na região selecionada para estudo, já que, como a produção ocorre majoritariamente em cadeia familiar, com bases culturais de produção, na grande maioria das vezes, falta um controle sanitário mais rígido, que atenda às normas estipuladas na legislação. Nesse aspecto, a imensa maioria dos produtores não conhecem as boas práticas de elaboração, mesmo estas sendo uma exigência prevista em lei e um fator importante para garantir uma produção higienizada e devidamente própria para consumo.

A importância de manter a cultura é indiscutível, porém, também é essencial e justo agregar valores culturais e legais, a fim de evitar quaisquer prejuízos às pessoas que investem na área e dedicam tempo e amor à produção, bem como às pessoas que gozam do vinho produzido, degustando saúde e riqueza cultural de qualidade em suas taças. 


\section{Determination of the quality of artisanal wines produced in the North-West Mesoregion of Rio Grande do Sul}

\section{Abstract}

Wine, is a drink obtained from alcohol fermentation of the mature/fresh grape or mature/fresh grape juice. Its biochemical definition is characterized as a coming drink from alcoholic fermentation of sugars of the grape juice by yeasts and, in some cases, by lactic bacteria. This research has the objective of understanding the real quality of artisanal wines which are marketed in trade shows or acquired straight from rural properties. The intention is to analyze quantatively by physical-chemical analysis, determining parameters such as: Alcoholic Content, total Red/ White Wine acidity, produced and marketed in north-west mesoregion of Rio Grande do Sul. This region contains a meaning amount of rural producers who produces wine to add value to their developed activities on its properties. Artisanal Wines are very consumed on the researched area because of their cultural reasons, due the sensory quality and the amount of health benefits it brings, when consumed moderately. In the case of the wine, the determination of the alcoholic content and acidity, it gives an important data of its conservation, once in the production one of the main problems is related to early acidification by transforming the alcohol into acetic acid, as soon as there is no effective control on the fabrication, such as in the conservation, given the good practices of fabrication are barely known.

Keywords: Physical-chemical analysis. Quality. Artisanal wine.

\section{Referências}

ALPUIM, J. P. Boletim da sociedade portuguesa de Química. Lisboa: JNICT, 1997. p. 13-27.

BACCAN, N. et al. Química analítica quantitativa elementar. São Paulo: Edgard Blücher, 2013.

BRASIL. Decreto $\mathrm{n}^{\circ}$ 8.198, de 20 de fevereiro de 2014. Regulamenta a Lei $\mathrm{n}^{\circ}$ 7678, de 8 de novembro de 1988, que dispõe sobre a produção, circulação e comercialização do vinho e derivados da uva e do vinho. Brasília, DF, 2014a.

BRASIL. Lei $\mathrm{n}^{\circ}$ 12.959, de 19 de março de 2014. Altera a Lei $\mathrm{n}^{\circ} 7678$, de 08 de novembro de 1988, para tipificar o vinho produzido por agricultor familiar ou empreendedor familiar rural, estabelecer requisitos e limites para sua produção e comercialização e definir diretrizes para 0 registro e a fiscalização do estabelecimento produtor. Brasília, DF, 2014b.

BRASIL. Ministério da Agricultura, Pecuária e Abastecimento. Portaria no ${ }^{\circ}$, de 18 de maio de 2016. Submete o Projeto de Instrução Normativa e Anexo que aprovam a complementação dos padrões de identidade e qualidade do vinho e derivados da uva e do vinho e definem a classificação das variedades de uvas. Brasília, DF: Ministério da Agricultura, Pecuária e Abastecimento, 2016.

CANAS, S. Phenolic composition and related properties of aged wine spirits: influence of barrel characteristics - a review. Beverages, v. 3, n. 4, p. 55, 2017. DOI: 10.3390/beverages3040055.

CATALUÑA, E. As uvas e os vinhos. São Paulo: Globo, 1988.

CÔRTE REAL, M. O ritual do vinho. Porto Alegre: AGE Ltda., 1993. 
DE CASTILHOS, M. B. M. Vinificação em tinto de uvas americanas: efeito das técnicas de pré-secagem das uvas e de chapéu submerso nos perfis químico e sensorial. Tese (Doutorado em Engenharia e Ciência de Alimentos) - Instituto de Biociências, Letras e Ciências Exatas, Universidade Estadual Paulista, São José do Rio Preto, 2016.

GAUTO, M. A.; ROSA, G. R. Processos e operações unitárias na indústria química. Rio de Janeiro: Ciência Moderna Ltda., 2011.

HARRIS, D. C. Análise química quantitativa. Rio de Janeiro: LTC, 2011a.

HARRIS, D. C. Explorando a química analitica. Rio de Janeiro: LTC, 2011 b.

INSTITUTO BRASILEIRO DO VINHO. Panorama da vitinicultura brasileira. Reunião da Câmara Setorial da Cadeia Produtiva da Viticultura, Vinhos e Derivados, Brasília, 1ํo de março de 2018. Disponível em: http://www.agricultura.gov.br/assuntos/camaras-setoriais-tematicas. Acesso em: 30 maio 2018.

MARTINS, G. G. et al. Sesquiterpene lactones of Moquiniastrum polymorphum subsp. floccosum have antineoplastic effects in Walker-256 tumor-bearing rats. Chemico-Biological Interactions, v. 228, p. 46-56, 25 fev. 2015.

MENDHAM, J. et al. VOGEL: análise química quantitativa. Rio de Janeiro: LTC, 2011.

RIZZON, L. A.; DALL'AGNOL, I. Coleção agroindústria familiar, vinho tinto. Brasília, DF: Embrapa, 2007.

SIMON, J. O livro do vinho. São Paulo: Editora Três, 2001.

SOUZA, F. A. Mudanças promovidas no setor vinícola do Rio Grande do Sul pela inserção de profissionais especialistas nas áreas viticultura e enologia. Dissertação (Mestrado em Ciências) - Programa de Pós-Graduação em Educação Agrícola, Universidade Federal Rural do Rio de Janeiro, Rio de Janeiro, 2005.

VACCARI, N. F. S.; SOCCOL, M. C. H.; IDE, G. M. Compostos fenólicos em vinhos e seus efeitos antioxidante na prevenção de doenças. Revista de Ciências Agoveterinárias, Lages, v. 8, n. 1, p. 1-13, 2009. 